\title{
Impact of Photonic Action on the Hygroscopy of Sweet Potato Starch-Based Bioplastics from Congo
}

\author{
Aristide H. W. Nakavoua ${ }^{1 *}$, Anicet F. Binaki², Emmanuelle S. Ouenadio ${ }^{3}$, Raymond G. Elenga ${ }^{4}$, \\ Vincent Verney ${ }^{5}$
}

\begin{abstract}
${ }^{1}$ Laboratory of Natural Substances Chemistry (IRSEN), Brazzaville, Congo
${ }^{2}$ Equipe Pluridisciplinaire en Alimentation et Nutrition, Pôle d'Excellence Régionale en Alimentation et Nutrition BP 389, Faculté de Sciences et Techniques, Brazzaville, Congo

${ }^{3}$ Laboratory for the Valorisation of Agri-Resources, Ecole Normale Superieure Politechnique (ENSP), Marien Ngouabi University, Brazzaville, Congo

${ }^{4}$ Laboratory for materials and Energy, Faculty of Science and Technology (FAST), Marien Ngouabi University, Brazzaville, Congo ${ }^{5}$ Institute of Chemistry of Clermont-Ferrand (ICCF), UMR 6296 Team Design of Polymers and Macromolecules Scientist Set Cézeaux24 Avenue des Landais, Clermont-Ferrand, France
\end{abstract}

Email: ^a.nakavoua@lycee-saintexbrazza.org

How to cite this paper: Nakavoua, A.H.W., Binaki, A.F., Ouenadio, E.S., Elenga, R.G. and Verney, V. (2022) Impact of Photonic Action on the Hygroscopy of Sweet Potato Starch-Based Bioplastics from Congo. Open Journal of Applied Sciences, 12, 42-50. https://doi.org/10.4236/ojapps.2022.121004

Received: December 2, 2021

Accepted: January 10, 2022

Published: January 13, 2022

Copyright $\odot 2022$ by author(s) and Scientific Research Publishing Inc. This work is licensed under the Creative Commons Attribution International License (CC BY 4.0).

http://creativecommons.org/licenses/by/4.0/

\begin{abstract}
The work carried out here opens another perspective in the valorization of sweet potatoes produced in Congo Brazzaville other than those proposed by BOULA and all. We have shown in this work that the hydrophilic property of starch which limits the production of starch-based bioplastics can be inhibited by using the effects of photonic incandescence. Indeed, light significantly impacts the bioplastic matrix causing a decrease of the sites likely to bind water molecules. However, it would be desirable to apply rheology for a better follow-up of this cross-linking phenomenon. The synthesized retrograde bioplastic having undergone a photonic stress shows better physical properties to be used as packaging and thus to answer the environmental protection.
\end{abstract}

\section{Keywords}

Aging, Bioplastic, Ipomea batata, Photonic Stress

\section{Introduction}

Plastics offer a wide range of properties and applications and are today an important or even indispensable material for many industries. The worldwide demand for this group of materials is constantly increasing, but so are the requirements in terms of performance and quality. 
In recent years, a special category of this group of materials, namely bioplastics, has attracted interest [1]. The race to bioplastics represents a major challenge for countries with a high diversity of agro-resources in the valorization of their starch products, which is accentuated by the desire for sustainable development and greater climate protection.

Plastic films based on starch are most often made by advanced hydrolysis, the principle is however based on the integration within the matrix of the macromolecule of a plasticizer [2]. However the synthesis of bio plastic by retrogradation is more and more experimented by integrating of course a plasticizer. It is this last possibility that we have exploited in this work.

Our bio plastics were obtained from sweet potato starch, a seasonal food that is very appreciated by the Congolese for its highly pronounced sweet taste compared to tubers or other starchy roots. This root is very rich in reducing sugar [3] and gives a very little studied starch, which confers to this work a slight empirical character, especially in its aspect of production of retrograded bio plastics based on sweet potato.

A non-negligible limit that makes the popularization of starch-based bioplastics is their affinity to water. This hydrophilic character of these plastics favors the activity of water and therefore the appearance of molds that eventually degrade the bioplastic [4].

Thus, the aim of this work is to propose a method to overcome more or less completely this hydrophilic character of bioplastics which is quite difficult to treat [5].

However, it must be emphasized that the results obtained during these different works have edified us but also confirm that one of the outlets of the sweet potato spinneret can be the one explored by our centers of interest that have given rise to this work.

\section{Material and Methods}

\subsection{Starch Extraction Process}

The starch used for the synthesis of bioplastic was extracted from the pulp of sweet potato Ipomea batata [6] procured on the TOTAL market place in Brazzaville.

After receiving the material (sweet potato), it is cleaned and peeled before being grated. The grated pulp thus recovered is placed in a container to which drinking water is added. This mixture was then filtered through a sieve. The filtrate obtained is submitted to a decantation and 2 hours later the supernatant is removed with a pipette; the starch obtained is air-dried for two days.

\subsection{Synthesis of Bioplastics}

Prepare in a pan, $300 \mathrm{~mL}$ of distilled water, $10 \mathrm{~mL}$ of glycerol and $15 \mathrm{~g}$ of starch. Mix and bring to boil until it becomes thick and translucent. Continue to heat for $10 \mathrm{~min}$ without stopping to stir with a wooden spatula. Pour the still hot and 
liquid mixture onto a glass plate. Allow to cool for one hour to allow bubbles to escape then place in the oven at $100^{\circ} \mathrm{C}$ for 24 hours.

\subsection{Sampling}

The sampling is carried out on the obtained bioplastics. We have two types of samples (Table 1).

- Type A; bioplastic of circular shape $3.5 \mathrm{~cm}$ of radius not having undergone the photonic stress.

- Type B; bioplastic of circular shape $3.5 \mathrm{~cm}$ of radius having undergone the photonic stress.

\subsection{Physico-Chemical Analyses}

The main physico-chemical analyses were determined with reference to international and French standards. Two types of bioplastic subjects were targeted in these analyses, those which underwent the different light stresses and those which did not undergo any stress at all.

We have thus realized,

$\checkmark$ The water content (AOAC 950.0, 1990),

$\checkmark$ The ash content (NF T 76-110 sept. 1981),

$\checkmark$ Hygroscopy: Measure a mass $m$ in grams of the bioplastic, expose to air and measure every 24 hours for 1 week. The hydroscopy is given by the difference of the initial mass and the final mass

Follow-up of hygroscopy during photonic stress by measuring the mass of the bioplastic every hour for 7 hours.

Biodegradation test: This test is carried out by placing $1 \mathrm{~g}$ of bioplastic for two months in glasses containing different types of earth: black, yellow and white to which we assign respectively the symbols $\mathrm{T}_{1}, \mathrm{~T}_{2}$, and $\mathrm{T}_{3}$. The black soil was taken from around the plantations; the yellow soil is of the clay type and the white soil of the marine type. Then, the mass of the bioplastic is measured again [7].

$$
T D(\%)=\frac{M_{0}-M_{1}}{M_{0}} \times 100
$$

$M_{0}$ : mass of film before degradation; $M_{1}$ : mass of film after degradation

\subsection{Simulation of Aging}

Light stress: Cut the bioplastic into a circle of $3.5 \mathrm{~cm}$ radius. Place the film in the chamber and measure the diameter every 10 minutes, reproduce the experiment 10 times. The aging chamber is a device specifically designed to simulate

Table 1. Summary of the different samples.

\begin{tabular}{ccc}
\hline Type & Samples & Description \\
\hline A & Ech 1 & Without photonic stress \\
B & Ech 4 & With photonic stress
\end{tabular}


solar aging on our bioplastic samples. It is a wooden box of $15.6 \mathrm{~cm}^{3}$ of volume whose interior is covered with a black plastic sheet. On the upper face is placed an incandescent lamp type Edison ( $15 \mathrm{~cm}$ from the sample) of power $100 \mathrm{~W}$ and capacity 210 lux, connected to an electric cable connected to a voltage regulator but also of a thermometer which indicates the temperature within the enclosure. The internal temperature $T_{i}$ is noted immediately after closing the chamber. The internal temperature $\mathrm{T}_{\mathrm{f}}$ is recorded again before opening the chamber.

\section{Results and Discussion}

\subsection{Starch Retrogradation and Bioplastic Formation}

Our variety of sweet potato, with a brown skin, is likely to provide consumers with $440 \mathrm{KJ}$ or $105 \mathrm{Kcal}$ per $100 \mathrm{~g}$ of potato [3]. More often used as a complementary food in Congo, it gave us an extraction yield of $9.5 \%$, which confirms that it is a root rich in starch, which is also easy to extract. However, this yield is rather low compared to the one given by Tshizembe and all on cassava tubers.

Like most of the products resulting from a retrogradation of starch in the presence of a plasticizer: glycerol, the films obtained have a rubbery aspect [8]. The resistance to touch seemed to us to be suitable. The thickness chosen by flattening two glasses reflects that changes have occurred within the matrix of the macromolecule.

The glycerol used as plasticizer does not interact chemically with the matrix in which it is dispersed. It simply increases the free volume between two polymer chains to reduce the interactions and thus promote the movement of one with respect to the other [9]. The presence of this plasticizer reduces heating because the plasticizer has already introduced free volume between the chains. The film is thus transformed from a rigid material into a plastic. The film obtained is thus more resistant to tension and bending. In addition, the addition of glycerol makes the film transparent, which is very useful for packaging purposes.

Heating serves to destructure the starch. Once destructured, the starch mixes easily with the glycerol. A destructured starch is a starch that is no longer in its original form of grain: the polymers constituting it (amylose and amylopectin) are dispersed. We notice a phase that gels quickly above another whose fluidity is greater. The first one should correspond to the behavior of amylose whose fusion occurs quickly and the other part to the behavior of amylopectin whose gelling is slower and limited because of its branched structure. This is what is actually observed, so we have indeed obtained a plastic film by retrogradation. Indeed, retrogradation refers to the structural reorganization (or recrystallization) that takes place during the cooling of a destructured starch suspension [10].

\subsection{Comparative Characteristics of Bioplastics}

The subjects who did not undergo the light stress show an average water content of $36.28 \%$ while those who underwent the light stress give an average content of $33.78 \%$. This result proves that the action of the lamp has a real effect on the 
water content. Indeed, an incandescent lamp produces light whose spectrum is close to that of the sun, but the efficiency between the luminosity of this type of lamp and the energy consumed is $10 \%$; this explains why these lamps produce a lot of heat, moreover the temperature within the box reaches on average $90^{\circ} \mathrm{C}$. There is therefore an increase in temperature during stress, which explains the large difference in the average water content returned during this work. It is also important to note that a new texture for our plastics, with a more rigid solid appearance and a more sustained elasticity, is observed. These observations show that real structural modifications occur within the matrix of our bioplastics [11]. Indeed, these modifications can be due to a reorganization of the structure by the development of a much more cross-linked network [12]. The number of cross-links in the matrix increases, making the structure stronger and therefore more able to resist certain external factors such as humidity.

The ability of our bioplastics to resist moisture is shown by hygroscopic analysis. We found that the light-stressed bioplastic showed the lowest values.

We can thus say that the structure of the bioplastic contains sites of various forms where water molecules are inserted. During stress, the bioplastic matrix undergoes a reorganization and modifies these different sites. These sites become less available to accommodate water molecules, resulting in a weaker hydroscopy and thus a better resistance to alteration (Figure 1). This result is very encouraging because one of the points limiting the impact of starch-based plastics is precisely their capacity to absorb the water vapor contained in the ambient air. Indeed, starch is very hydrophilic, which is a real challenge for professionals in the field.

Light stress is a significant alternative to this limitation, and further confirmatory analyses are required [13].

The light-stressed bioplastic matrix has formed a crystal lattice. The crosslinking caused by the effects of light considerably removes the sites that could receive water molecules from the air. Thus, a more compact and better organized structure was formed [14].

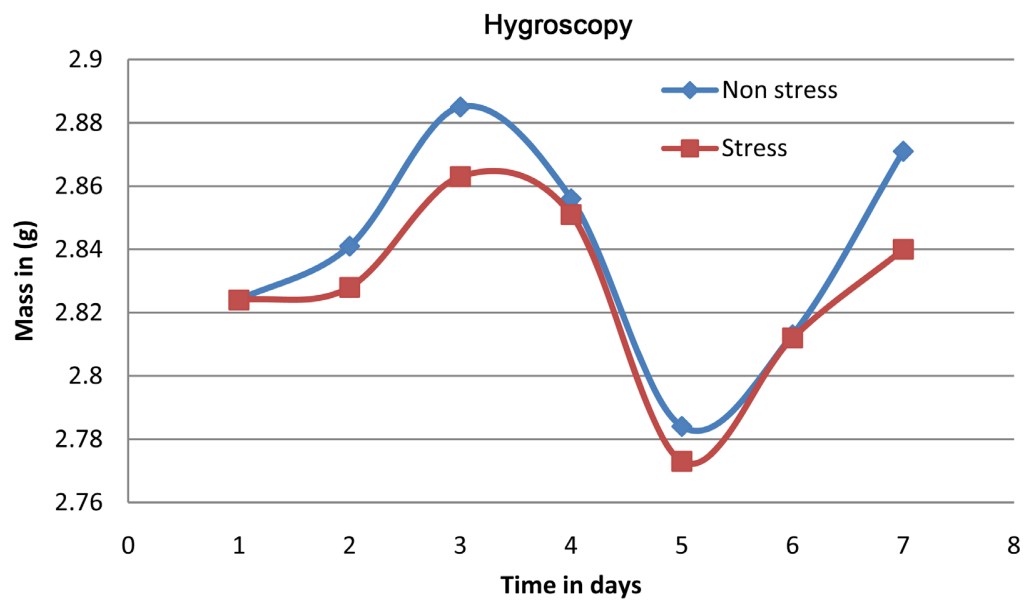

Figure 1. Hygroscopy of bioplastics. 
However, it was noted that exposure to light stress did not change the intrinsic composition of our bioplastic, only the bioplastic matrix was the site of a change. Indeed, the ash content remained almost the same for both types of bioplastics analyzed (Table 2).

The observation of the intrinsic composition which remains unchanged leads us to think that the behavior of our bioplastics in front of the natural degradation should also remain unchanged. Thus, three tests were carried out and revealed that light stress considerably strengthens the resistance to biodegradation. The longevity of our bioplastics is thus improved, this result may seem anecdotal but is in agreement with the new structuring of the bioplastic thus obtained.

Bioplastics not exposed to light stress generally underwent greater biodegradation. These results are consistent with the findings of previous analyses.

The degradation kinetics of bioplastics is accelerated by water activity. A bioplastic that is poor in binding sites for water molecules offers a better resistance profile to microorganisms. The newly formed cross-link network is also a major contributor to biodegradation resistance [14]. However, the latter remains (Table 3), otherwise the interest in producing bioplastics would no longer exist. These results show moreover, that the soil (marine soil) $\mathrm{T}_{3}$ is the one in which this biodegradability is the most attenuated, this is in agreement with the behavior of this type of soil with regard to the retention of water. Indeed, the marine type soil does not retain water and in the absence of water the bioplastic undergoing stress is in ideal conditions to preserve its state for a longer period of time, moreover this type of soil contains few microorganisms. Contrary to the black soil which is very rich in humus and therefore in microorganisms and retains considerably the water runoff.

When the bioplastic is left in the enclosure for 7 hours, it shows a behavior reminiscent of the Gaussian curve, part of the water vapor contained in the enclosure is initially integrated into the matrix of the bioplastic, hence the increase of the mass. After two hours, we notice that the mass of the sample decreases, this decrease continues until a plateau is established around $2.79 \mathrm{~g}$ (see Figure 2). This behavior confirms that the bioplastic matrix undergoes a considerable modification which prevents the fixation of the water contained in the air although at each opening of the enclosure this air is renewed.

Table 2. Ash content results.

\begin{tabular}{cc}
\hline Type of bioplastic & Ash content in \% \\
\hline Without stress & 2.42 \\
With stress & 2.41 \\
\hline
\end{tabular}

Table 3. Results of the biodegradation test.

\begin{tabular}{cccc}
\hline Type of bioplastic/type of soil & $\mathrm{S}_{1}$ & $\mathrm{~S}_{2}$ & $\mathrm{~S}_{3}$ \\
\hline Without stress & $11.9 \%$ & $56.1 \%$ & $7.8 \%$ \\
With stress & $16.1 \%$ & $65.6 \%$ & $21.3 \%$ \\
\hline
\end{tabular}




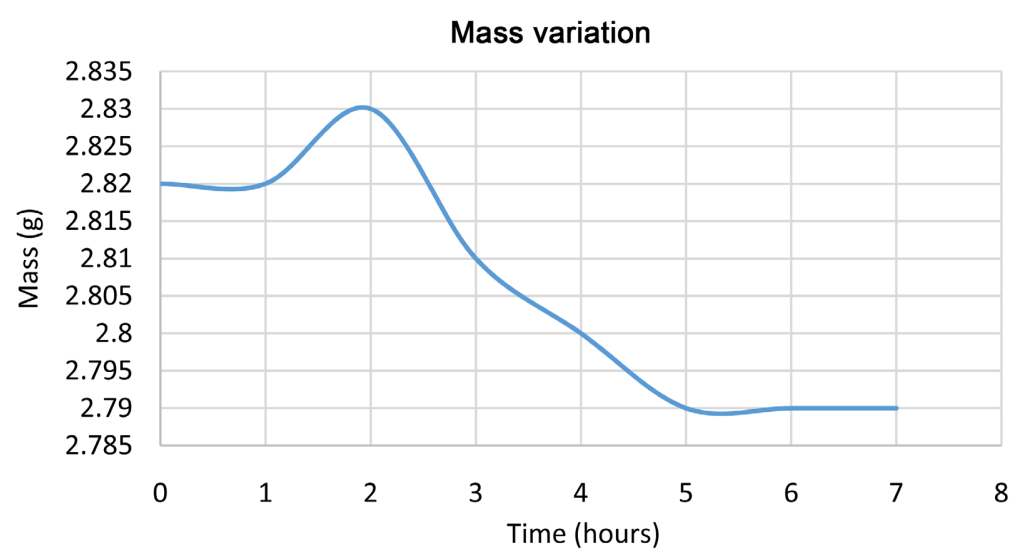

Figure 2. Bioplastic facing the water vapor contained in the enclosure.

\section{Conclusions}

In Congo-Brazzaville, many studies on starch roots have had the merit of enhancing the value of local products and opening up avenues for their popularization on a national scale. Thus, many authors have reported on tubers and sweet potatoes, particularly for their food value [15]. The work carried out here opens another perspective in the valorization of sweet potatoes produced in Congo Brazzaville. Indeed, the bioplastic synthesized from sweet potato starch can be used in the production of packaging, however it is hydrophilic. We have shown during this work that the hydrophilic property of starch which limits the production of starch-based bioplastics can be inhibited through the use of photonic incandescence effects. The bioplastic produced from sweet potato starch subjected to the effects of the Edison type lamp not only loses water but also can no longer absorb it. Indeed, the light significantly impacts the bioplastic matrix causing a decrease of the sites likely to fix the water molecules. However, it would be desirable to apply rheology for a better monitoring of this phenomenon of cross-linking but also to pass the matrix to the electron microscope to observe the effects on the nanostructure of the bioplastic. Within the framework of the valorization of this product of the soil, it is important to underline the production of stabilized bioplastics and not hydrophilic biodegradable and having a strong sweet character.

The synthesized retrograde bioplastic having undergone photonic stress shows better physical properties to be used as packaging [16] and thus responds to the environmental protection.

The perspectives of this work open up in the vision of analyzing the behavior of coloured bioplastics subjected to photonic stress. But also, redo the work using the rheology apparatus. Eventually think about using the clones of sweet potatoes in the manufacture of bioplastics [17].

\section{Conflicts of Interest}

The authors declare no conflicts of interest regarding the publication of this paper. 


\section{References}

[1] Lévêque, E., Haye, B. and Belarbi, A. (2000) Starch and Its Derivatives. Elsevier, Amsterdam.

[2] Djetoui, Z. and Djerboua, F. (2012) Preparation of a Biodegradable Thermoplastic Polymer Based on Corn Starch. 3rd International Conference on Welding, NDT and the Materials and Alloys Industry (IC-WNDT-MP 12), Oran, 26-28 November 2012, 104.

[3] Vodouhe-Egueh, S., Alidou, C., Aboudou, K. and Soumanou, M.M. (2017) Formulation of Cookies Based on Wheat Flour Enriched with Orange Flesh Sweet Potato Flour. Africa Science, 13, 405-416.

[4] Abinader, G., Lacoste, C. and Erre, D. (2016) Elaboration of Cushioning Plates from Agro-Resources by Reactive Extrusion: Optimization of Process-Structure-Property Relationships. Journal of Composites and Advanced Materials, 26, 383-400.

[5] Georges, A., Lacoste, C. and Damien, E. (2018) Effect of Formulation and Process on the Extrudability of Starch-Based Foam Cushions. Industrial Crops and Products, 115, 306-314. https://doi.org/10.1016/j.indcrop.2018.02.001

[6] Oladebeye, A.O., Oshodi, A.A. and Oladebeye, A.A. (2009) Physicochemical Properties of Sweet Potato (Ipomea batata) and Red Cocoyam (Colocasia esculenta) Corm Starches. Pakistan Journal of Nutrition, 8, 313-315.

https://doi.org/10.3923/pjn.2009.313.315

[7] Jbilou, F., Joly, C., Galland, S., Belard, L., Desjardin, V., Bayard, R., et al. (2013) Biodegradation Study of Plasticized Blends of Corn Meal and Poly (butylene succinateco-butylene adipate). Polymer Testing, 32, 1565-1575.

https://doi.org/10.1016/j.polymertesting.2013.10.006

[8] Das, A.B., Singh, G., Singh, S. and Riar, C.S. (2010) Effect of Acetylation and Double Modification on Physicochemical, Rheological and Morphological Characteristics of Sweet Potato (Ipomoea batatas) Starch. Carbohydrate Polymers, 80, 725-732. https://doi.org/10.1016/j.carbpol.2009.12.018

[9] Rouilly, A. and Rigal, L. (2002) Agro-Materials: A Literature Review. Journal of Macromolecular Science, Part C: Polymer Reviews, 42, 441-479.

https://doi.org/10.1081/MC-120015987

[10] Wertz, J.L. and Goffin, B. (2020) Starch in the Bioeconomy. CRC Press, Boca Raton.

[11] Mufeng, L.N.D., Batiango, J.N., Ndongala, C.M. and Ndyanabo, J.T.M. (2020) Effect of Temperature and Gamma Irradiation on the Viscosity of Starch Three Varieties of Cassava (Manihot Esculenta Crantz). African Journal of Environment and Agriculture, 3, 121-128.

[12] Guo, J.J., Lian, X.J., Kang, H.Q., Gao, K. and Li, L. (2016) Effects of Glutenin in Wheat Gluten on Retrogradation of Wheat Starch. European Food Research and Technology, 242, 1485-1494. https://doi.org/10.1007/s00217-016-2649-5

[13] Yadav, K., Yadav, B.S., Yadav, R.B. and Dangi, N. (2018) Physicochemical, Pasty and Rheological Properties of Colocasia Starch Influenced by the Addition of Guar Gum and Xanthan Gum. Journal of Food Measurement and Characterization, 12, 2666-2676. https://doi.org/10.1007/s11694-018-9884-3

[14] Gaudin, S., Commereuc, S., Verney, V., Guyonnet, R. and Govin, A. (2007) Durability of Biodegradable Wood-Polymer Composites. Materials \& Techniques, 95, 143-148.

[15] Boula, E.F.M., Mananga, V., Elenga, M. and Kinkela, T. (2016) Study of the Dietary Habits of Households in Brazzaville for the Control of Vitamin A Deficiency. Jour- 
nal of Applied Biosciences, 97, 9174-9186. https://doi.org/10.4314/jab.v97i1.4

[16] Elenga, R.G., Djemia, P., Tingaud, D., Chauveau, T., Maniongui, J.G. and Dirras, G.F. (2013) Effects of Alkali Treatment on the Microstructure, Composition and Properties of Raffia Textilis Fiber. BioResources, 8, 2934-2949.

https://doi.org/10.15376/biores.8.2.2934-2949

[17] Tshizembe, D.M., Jadika, C.T., Ngeleka, T.T., Mbaji, A.K.N.A., Bongali, A.B. and Mutombo, S.B. (2018) Évaluation des clones de manioc à pulpe jaune pour leur teneur en $\beta$-carotène, rendements en tubercules frais et teneur en matière sèche à Ngandajika en République Démocratique du Congo. Journal of Applied Biosciences, 124, 12497-12505. https://doi.org/10.4314/jab.v124i1.11 